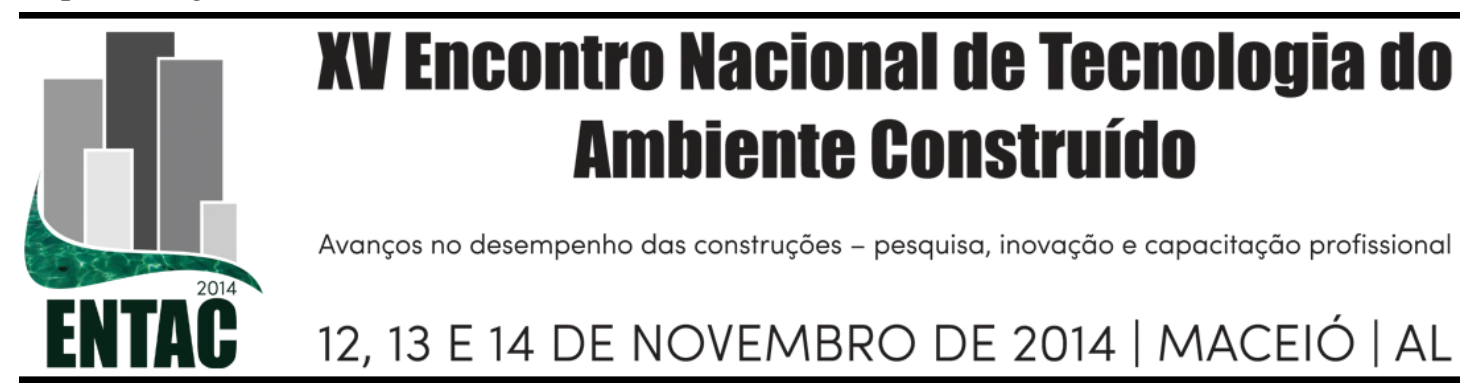

\title{
ANÁLISE DO ERRO NA PROJEÇÃO DE SOMBRAS EM HELIODON COM RAIO E MESA FIXOS
}

\author{
FERNANDES, Leandro C. (1); GRZYBOWSKI, Jose M. V. (2); RIBEIRO, \\ Anderson A. G. A. (3); SAUGO, Andréia (4); KRÜGER, Eduardo L. (5) \\ (1) UFFS/UTFPR, 54-3321-7050, e-mail: fernandes.uffs@gmail.com , (2) UFFS, \\ jose.grzybowski@uffs.edu.br, (3) UFFS, andersonribeiro@uffs.edu.br, (4) UFFS, \\ andreia.saugo@uffs.edu.br, (5) UTFPR, 41-33104725, ekruger@utfpr.edu.br
}

\begin{abstract}
RESUMO
Projetos de edificações visando condições térmicas e lumínicas adequadas devem prever o controle da insolação. Para isso são utilizados: softwares; aparelhos simuladores das trajetórias solares aparentes (heliodons); e cálculos apoiados em cartas solares, tabelas e processos de geometria descritiva. Este trabalho apresenta estudo utilizando heliodon com raio e mesa fixos objetivando: 1) determinar o impacto das diferenças geométricas entre os movimentos solares aparentes e os movimentos do simulador; 2) analisar os erros dimensionais de sombras projetadas em superfícies horizontais e verticais. Como método, realizou-se: modelagem matemática da projeção de sombras pelo aparelho e pelo Sol; e comparou-se as dimensões das sombras projetadas pelas duas fontes luminosas em diferentes situações. Verificou-se que o impacto das diferenças geométricas entre os movimentos solares aparentes e os movimentos do simulador é pouco significativo. A análise dos erros dimensionais das sombras projetadas confirmou a necessidade de cuidados quanto aos raios luminosos divergentes, dimensões e posicionamento da maquete. Para o aparelho utilizado os erros serão maiores em alturas solares próximas de $0^{\circ}$ (nascer/pôr do sol) e $90^{\circ}$ (zênite).Quanto às margens de erro, foi possível identificá-las para diversas alturas de maquetes e alturas solares. O estudo confirma a vocação do "heliodon de raio e mesa fixos" enquanto alternativa didática, mas aponta a necessidade de cuidados em se tratando das dimensões da maquete quando a precisão for importante para o experimento. Esta pesquisa traz contribuição para o dia a dia dos docentes e usuários do equipamento.
\end{abstract}

Palavras-chave: heliodon de raio e mesa fixos, simulador de trajetória solar aparente, equipamento didático.

\begin{abstract}
Projects aimed at providing adequate thermal and luminosity conditions should consider the control of heatstroke. Some tools can be employed towards this end, such as softwares, simulators of the apparent solar trajectories (heliodons), calculations supported by solar charts, tables and descriptive geometry procedures. This paper presents a study of a heliodon model with fixed radius and table. The objectives of the paper are to identify the causes for error in shadow projections, to determine the impact of differences between apparent solar movements and the movements of the simulator when it comes to dynamics and geometry and to analyze the dimensional errors of shadows projected on horizontal and vertical surfaces. The methodology adopted was the mathematical modeling of shadow projection by instrument and the Sun and the comparative of the dimensions of the shadows cast by the two light sources in different situations. It was found that the impact of the differences between the apparent solar movement and the movement of the simulator has little influence upon the error. The analysis of the dimensional errors of the shadows cast confirmed the need to regard the diverging light rays, the dimensions and positioning of the model. Errors were found to be larger at solar heights near zero degrees (sunrise/sunset), at 90 degree (zenith). The study confirms the feasibility of heliodons of fixed radius and table as teaching alternatives, while it also points to the need for caution when it comes to the
\end{abstract}


size and position of the models analyzed, especially in studies that require high precision. In this sense, this study brings contributions to teachers and other users of the equipment.

Keywords: Heliodon with fixed radius and table, simulators of the apparent solar trajectories, didactic equipment.

\section{INTRODUÇÃO}

Parte significativa do consumo energético de uma edificação ocorre para satisfazer necessidades humanas de aquecimento, resfriamento e iluminação (CUNHA, 2006). O consumo pode ser maior ou menor conforme o projeto arquitetônico tira partido do clima no qual a edificação está inserida. Olgyay (2008, p.10), quando relaciona arquitetura, clima e necessidades humanas, argumenta que "o processo lógico é trabalhar com as forças da natureza e não contra elas, aproveitando suas potencialidades para criar condições de vida adequadas". Edificações concebidas com essa idéia são denominadas por Olgyay como "climaticamente equilibradas". Entre os aspectos de interesse para esse tipo de projeto está o controle da radiação solar. Para controlar a incidência de radiação é necessário conhecer sua dinâmica, as variações ao longo das horas, dias, meses e estações.

Para entendimento e controle da incidência solar são três os meios principais nas escolas e escritórios de arquitetura:

- softwares;

- aparelhos simuladores das trajetórias solares aparentes (heliodons);

- cálculos apoiados em cartas solares, tabelas e processos de geometria descritiva.

Os três meios são importantes e complementares. Os heliodons facilitam significativamente o entendimento da geometria solar pelos estudantes. "Trata-se de dispositivo desenvolvido para simular a geometria solar e permitir o estudo de sombreamento através de modelos reduzidos" (SZOKOLAY, 2007, p.44). Nestes, utilizando maquetes, o usuário é capaz de simular condições de insolação em diferentes latitudes, dias do ano e horários. Permitem simular a incidência solar em escalas diversas, desde áreas urbanas até elementos construtivos como brises ou cobogós (FERNANDES e CUNHA, 2011).

No entanto, as diferenças de escala entre as distâncias "maquete/lâmpada" e "objeto arquitetônico/Sol" costumam gerar questionamentos por parte dos estudantes. Estes são reforçados quando percebida a simplificação dos movimentos simulados pelo aparelho quando comparados com os movimentos do astro. Embora o heliodon de raio e mesa fixos (Figura 1) seja bastante utilizado nas escolas de arquitetura e urbanismo, a bibliografia existente deixa de definir com precisão os limites de sua aplicação. Esta lacuna é motivo de insegurança de docentes e discentes quanto à validade dos experimentos realizados. Este artigo busca: 1) identificar os fatores de erros nas projeções de sombras; 2) determinar o impacto das diferenças geométricas entre os movimentos solares aparentes e os movimentos do simulador; 3) analisar os erros dimensionais de sombras projetadas em superfícies horizontais e verticais, relacionando: raios luminosos divergentes e dimensões das maquetes.

\section{METODOLOGIA}

A dinâmica dos movimentos aparentes do Sol em torno da Terra é excessivamente complexa para ser simulada perfeitamente em aparelhos didáticos de baixo custo. Os 
fatores de erro são diversos e interagem entre si. Mas, aceitando certas diferenças e alguma margem de erro, pode-se tirar proveito do uso dos simuladores. São causas de erro na projeção de luz e sombra no heliodon:

- incapacidade de simular a geometria dos movimentos solares aparentes em toda sua complexidade;

- diferenças entre os raios luminosos do Sol (paralelos) e os da lâmpada (divergentes);

- dimensões da maquete em comparação com a distância à fonte luminosa;

- posicionamento da maquete.

Foram estabelecidas as seguintes etapas para a quantificação dos erros:

a) Determinação do impacto das diferenças entre a geometria dos movimentos solares aparentes e dos movimentos do simulador;

b) Analise, através de modelos matemáticos, dos erros dimensionais das sombras projetadas em superfícies horizontais e verticais, relacionando os fatores: raios luminosos divergentes e dimensões das maquetes.

\subsection{Apresentação do aparelho}

O aparelho analisado, heliodon de raio e mesa fixos, também denominado heliodon de arcos, é propriedade de instituição de ensino superior em Curitiba, Paraná. Possui 1,5 m de raio e 36 lâmpadas (Figura 1). Tomando o raio $(\mathrm{R}=150 \mathrm{~cm})$ como referência, foram realizados testes para objetos com as seguintes alturas:
$1,0 \%$ de $\mathrm{R}$ ou $1,5 \mathrm{~cm}$;
$10,0 \%$ de $\mathrm{R}$ ou $15 \mathrm{~cm}$
$20,0 \%$ de $\mathrm{R}$ ou $30 \mathrm{~cm}$;
$2,5 \%$ de $\mathrm{R}$ ou $3,75 \mathrm{~cm}$;
$12,5 \%$ de $\mathrm{R}$ ou $18,75 \mathrm{~cm}$;
$22,5 \%$ de $\mathrm{R}$ ou $33,75 \mathrm{~cm}$;
$5,0 \%$ de $\mathrm{R}$ ou $7,5 \mathrm{~cm}$;
$15,0 \%$ de $\mathrm{R}$ ou $22,5 \mathrm{~cm}$;
$25,0 \%$ de $\mathrm{R}$ ou $37,5 \mathrm{~cm}$.

$7,5 \%$ de $\mathrm{R}$ ou $11,25 \mathrm{~cm}$;

$17,5 \%$ de $\mathrm{R}$ ou $26,25 \mathrm{~cm}$;

Figura 1 - Heliodon de raio e mesa fixos ou heliodon de arcos

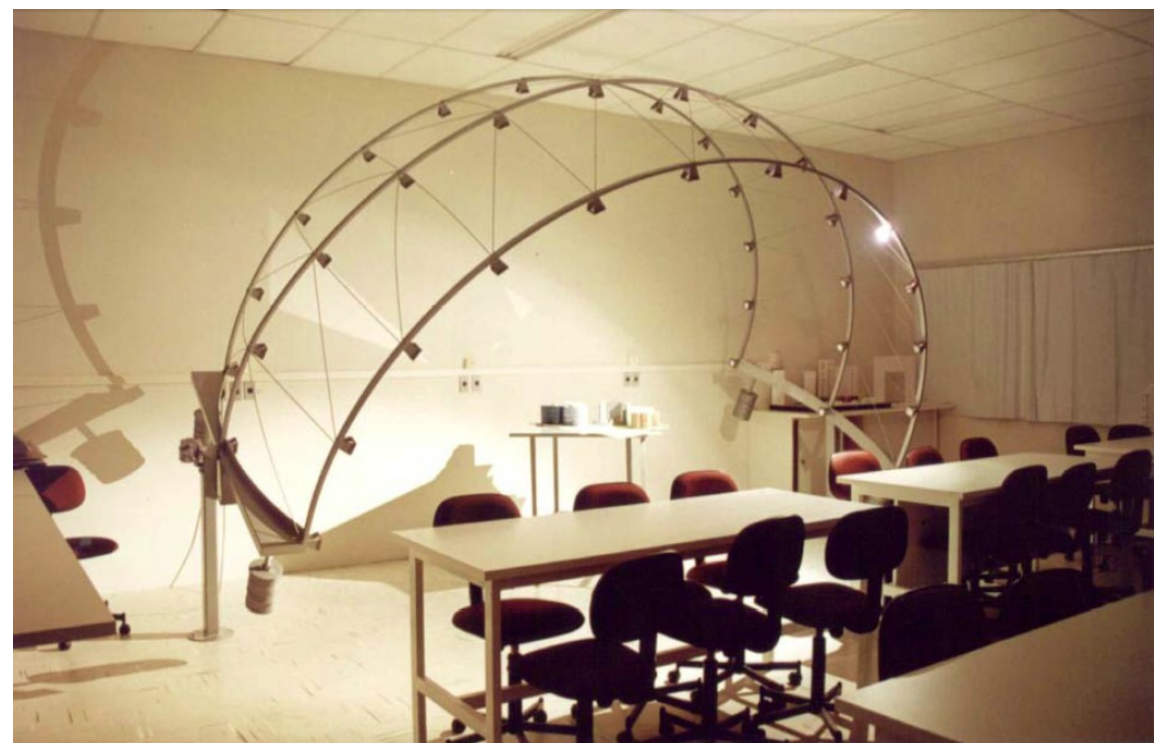

Fonte: Eliane Dumke 


\subsection{Impacto das diferenças entre a dinâmica e geometria dos movimentos solares aparentes e os movimentos e geometria do simulador}

Sabe-se que a órbita da Terra é levemente elíptica. Mas a excentricidade é muito pequena $(\mathrm{e}=0,01671123)$. Tão pequena que para efeitos práticos a órbita pode ser tomada como circular. Ao longo da órbita, a menor distância do Sol até a Terra, no periélio, é de aproximadamente $147.098 .290 \mathrm{~km}$. E a maior, no afélio, é de aproximadamente $152.098 .232 \mathrm{~km}$ (BRUMFIEL, 2012). Ou seja, a variação máxima é de aproximadamente $5.000 .000 \mathrm{~km}$. Relacionando com o heliodon, onde a lâmpada está a $150 \mathrm{~cm}$ do centro geométrico, corrigir a distância nos dias correspondentes ao afélio e ao periélio seria aproximar $5 \mathrm{~cm}$ em dado momento e afastar em outro. A implicação dessa variação de distância sobre o erro na projeção de sombras é insignificante.

A maior implicação do fato de a órbita ser elíptica, e que exige atenção, é relativa à variação da velocidade angular da terra ao longo de seu movimento de translação. De acordo com a $2^{\mathrm{a}}$ Lei de Kepler, ocorre aceleração quando a terra está mais perto do sol e desaceleração quando mais distante (SAMPAIO e CALÇADA, 2005). Isso gera diferenças significativas entre o horário relativo ao tempo solar aparente, do heliodon, e o horário oficial, relativo ao fuso horário vigente no local. Mas não implica em erros na projeção em si, embora sejam necessárias as conversões quanto aos horários.

\subsection{Erros dimensionais das sombras projetadas}

O aparelho analisado, como a maior parte dos simuladores de trajetória solar aparente, utiliza fonte luminosa pontual. Trata-se de uma importante causa de erro no dimensionamento de sombras. O erro será maior quanto maior for o tamanho do objeto analisado em relação à distância do centro geométrico do aparelho até a fonte luminosa e quanto mais o objeto estiver afastado desse centro geométrico.

\subsubsection{Caso 1 - Projeções no plano horizontal - Haste vertical}

Ocorrem quando o objeto de interesse (Figuras 2), posto no centro da mesa, é essencialmente vertical (torre, haste...) ou for posicionado de forma que a face maior esteja perpendicular aos raios do nascente e do poente (Ex. face de um muro).

Figura 2 - Objeto vertical centralizado

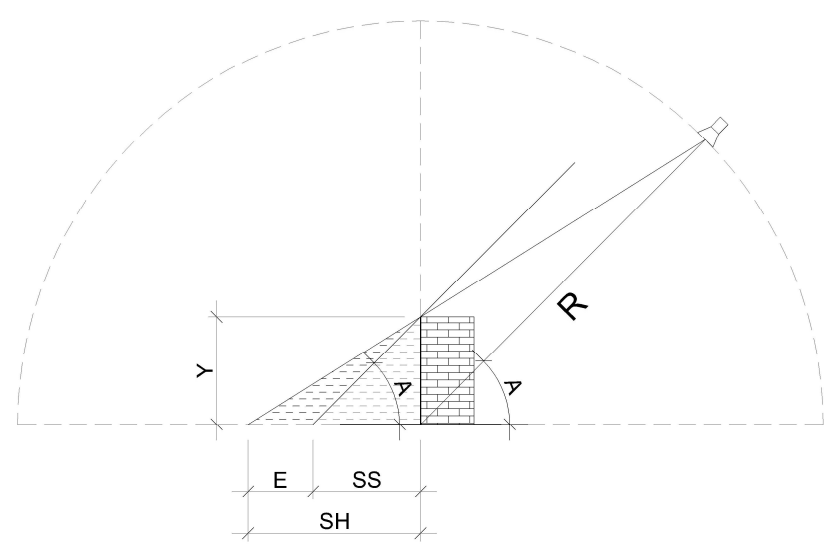

Para esta situação foram utilizadas as seguintes expressões:

$$
\begin{aligned}
& S H=Y \frac{R \cos A}{R \operatorname{sen} A-Y} \\
& S S=Y \cot A \\
& E=S H-S S \\
& E \%=\frac{S H-S S}{S S}
\end{aligned}
$$

E\% também pode ser obtido por:

$$
E \%=\frac{Y}{R \operatorname{sen} A-Y}
$$

Onde:

$\mathrm{A}=$ ângulo do raio luminoso projetado no centro geométrico do aparelho, equivalente ao ângulo solar; 
$\mathrm{R}=$ distância do centro geométrico até a fonte luminosa;

$\mathrm{Y}=$ altura do objeto testado;

$\mathrm{SH}=$ sombra projetada pelo heliodon (Equação 1);

$\mathrm{SS}=$ sombra projetada segundo o ângulo A, relativo à altura solar (Equação 2);

$\mathrm{E}=$ diferença entre a sombra projetada no aparelho e a projetada por raios paralelos (Equação 3);

$\mathrm{E} \%$ = razão entre E e SS (Equações 4 e 5).

2.3.2. Caso 2 - Projeções no plano horizontal - objeto com altura e largura

Ocorrem quando o objeto de interesse, colocado no centro da mesa, possui altura, largura e profundidade (Figura 3).

Figura 3 - Objeto com altura, largura e profundidade centralizado

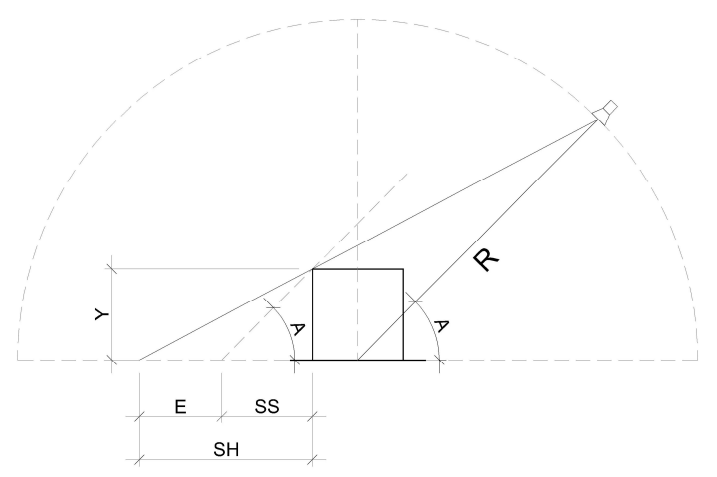

Para o cálculo de SH foi utilizada a Equação 6:

$$
S H=Y \frac{R \cos A+\frac{X}{2}}{R \operatorname{sen} A-Y}
$$

Onde:

$\mathrm{X}=$ largura do objeto analisado.

Para cálculo do erro percentual foram consideradas as Equações 2, 4 e 6.

2.3.3 Caso 3 - Projeções no plano vertical

Ocorrem quando o objeto de interesse simula um brise, beiral, toldo ou elemento arquitetônico do gênero (Figura 4).

\section{Figura 4 - Objeto vertical/horizontal}

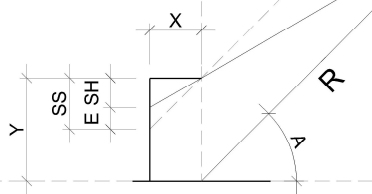

Foram utilizadas as Equações 7, 8, 9 e 10:

$$
\begin{aligned}
& S S=X \tan A \\
& S H=X\left(\frac{R \operatorname{sen} A-Y}{R \cos A}\right) \\
& E \%=\frac{S S-S H}{S S}
\end{aligned}
$$

$\mathrm{Ou}$

$$
E \%=\frac{Y}{R \operatorname{sen} A}
$$




\section{ANÁLISE DE RESULTADOS}

\subsection{Caso 1 - Sombras projetadas no plano horizontal - objeto vertical}

Na Figura 5 as linhas representam o erro percentual (E\%) em função da altura solar (A), supondo um " $R$ " constante igual a 1,5 m.

Sombras de objetos verticais projetadas em superfícies horizontais serão maiores quanto menor for a altura solar (ângulo A), tendendo ao infinito em ângulos próximos de $0^{\circ}$. Sombras excessivamente grandes quando comparadas com o objeto que as gera terão pouca aplicação, pois geralmente o objetivo é avaliar o sombreamento apenas no entorno próximo. Assim, determinou-se uma faixa de alturas solares de maior aplicação prática. Considerou-se razoável trabalhar com sombras menores que 2 vezes o tamanho do objeto. Ou seja, para a análise do erro desconsiderou-se alturas solares menores que $26,5^{\circ}$ (Figura 5).

Fig. 5 - Erro percentual X Altura solar

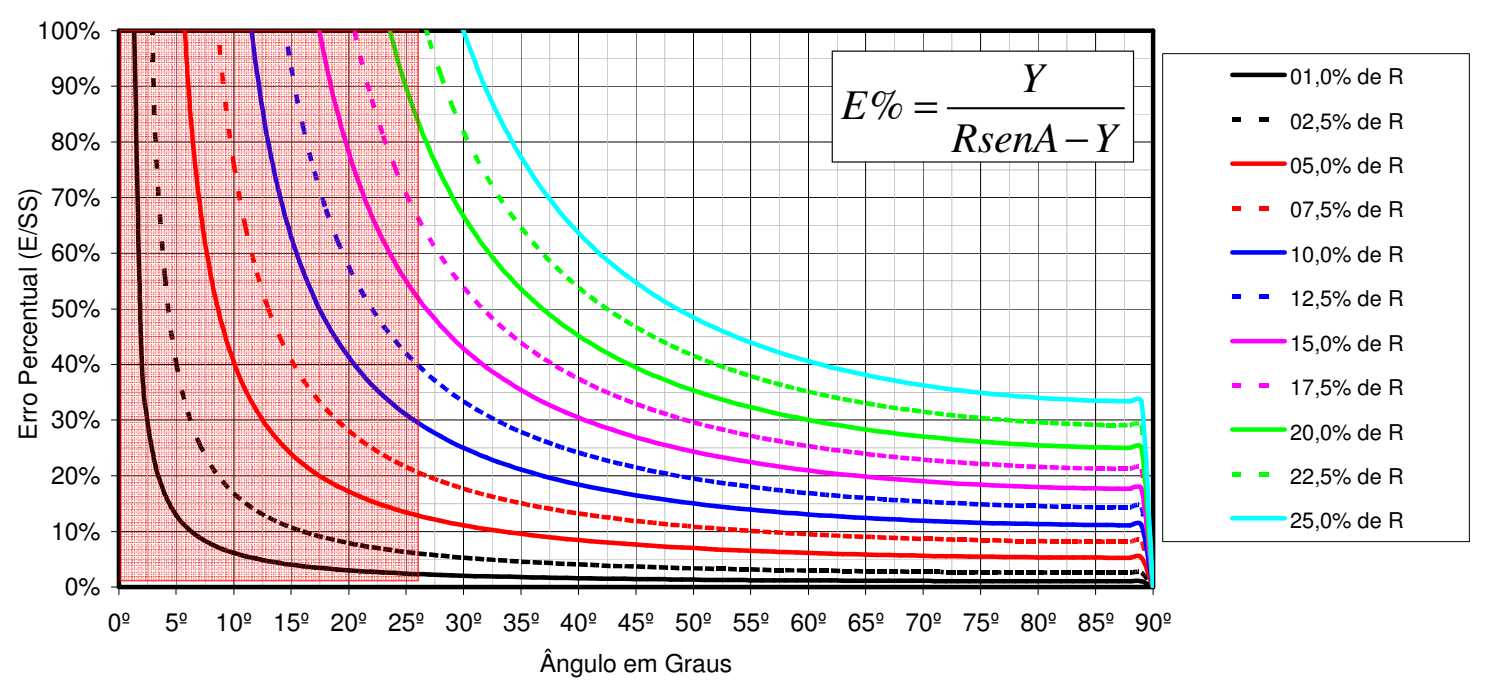

No caso 1, para trabalhar com erro menor que $10 \%$ a altura máxima da haste será aproximadamente $5,5 \mathrm{~cm}$ ou $3,75 \%$ de $\mathrm{R}$ (entre as linhas $2,5 \%$ e $5,0 \%$ ), considerando $\mathrm{R}=150 \mathrm{~cm}$ no aparelho. Para erros menores que $20 \%$ a altura máxima será $11,25 \mathrm{~cm}$ ou $7,5 \%$ de $\mathrm{R}$.

Fica evidente que a confiabilidade das projeções aumenta conforme aumenta a altura solar. Mas, mesmo em grandes alturas solares, objetos com mais que $10 \%$ de R (neste estudo maiores que $15 \mathrm{~cm}$ ) apresentarão sombras com erros maiores que $10 \%$.

Em virtude disso a altura máxima da maquete deverá ser definida pelo usuário (estudante, pesquisador...) em função da margem de erro aceita para o experimento.

A Figura 6 apresenta o erro $(\mathrm{em} \mathrm{cm}$ ) em função das alturas solares. Percebe-se que o erro diminui com o aumento da altura solar. Ou seja, quanto maior o ângulo, menor será a importância do erro absoluto $(\mathrm{em} \mathrm{cm}$ ) quando comparado com o tamanho da maquete. 
Fig. 6 - Erro em cm X Altura solar

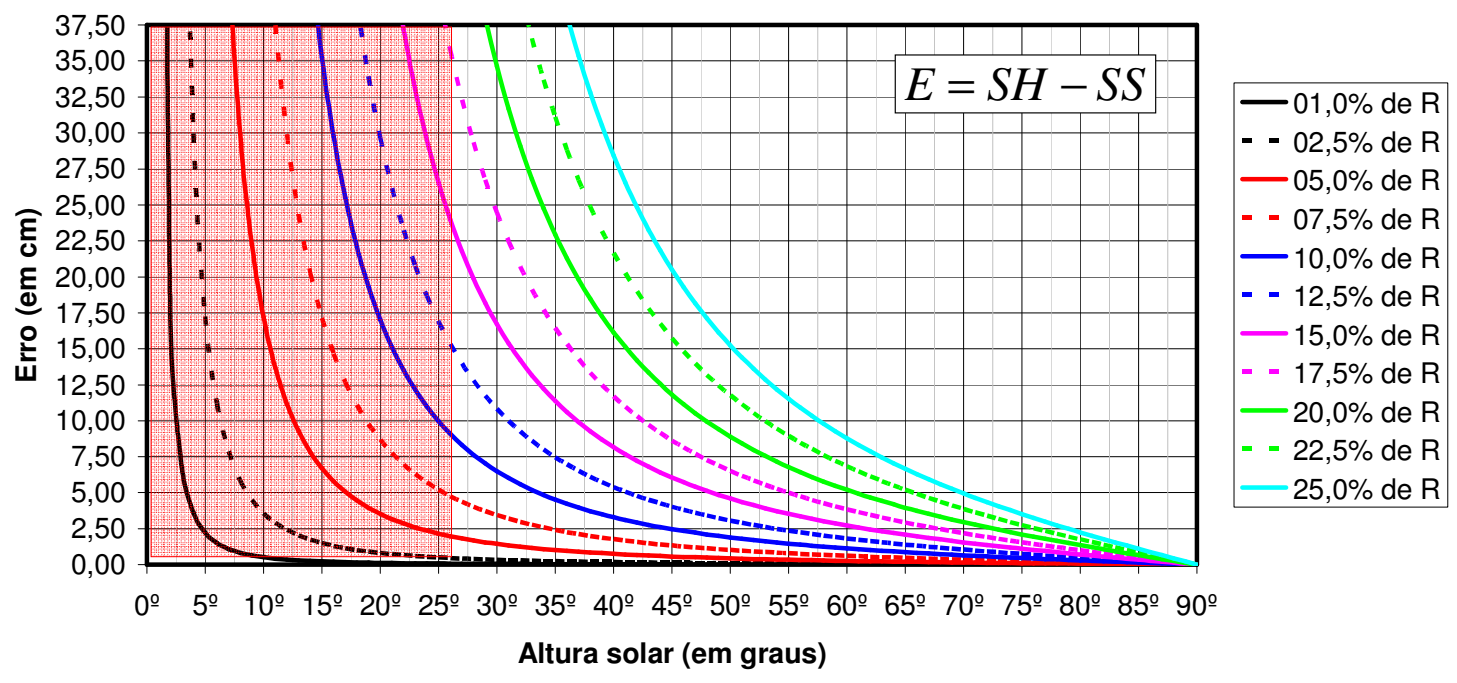

3.2 Caso 2 - Sombras projetadas no plano horizontal - objeto com altura e largura

A Figura 7 mostra que neste caso o erro é grande nas alturas solares baixas (próximas de $0^{\circ}$ ) e também nas altas (próximas de $90^{\circ}$ ). Neste caso o crescimento do erro em grandes alturas solares se deve ao fato das sombras geradas pelo Sol tenderem a zero próximas de $90^{\circ}$, enquanto que as do aparelho, embora diminuam significativamente, não cheguem a zero.

Examinando a Figura 8 percebe-se que, em comparação com a altura do objeto testado (Y), o erro (E) em valores absolutos diminui a ponto de tornar-se insignificante próximo da altura solar $90^{\circ}$, especialmente para os objetos de menores dimensões, embora o erro percentual apresente valores altos (Figura 7). Para uma análise objetiva do erro percentual (E/SS), excluindo alturas solares em que o erro percentual é grande, mas o erro absoluto é pouco significativo, resolveu-se desconsiderar os erros percentuais relativos aos ângulos maiores que $65^{\circ}$ (conforme faixa vermelha no gráfico).

\section{Figura 7 - Erro percentual X Altura solar}

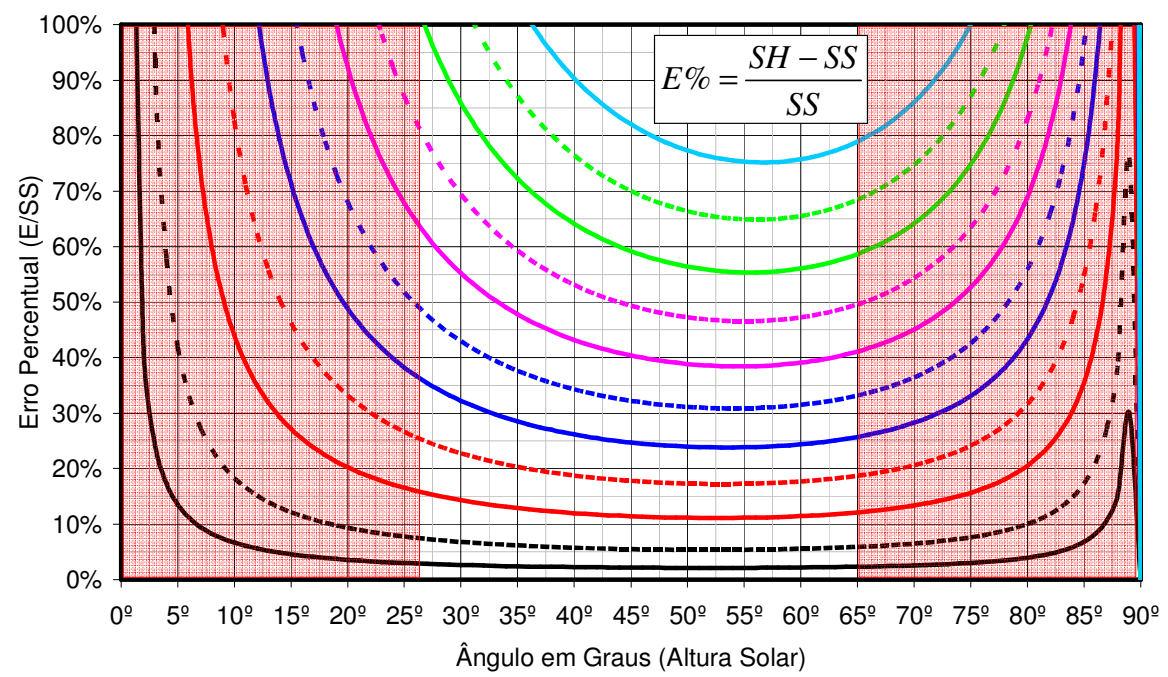


Fig. 8 - Erro em cm X Altura solar

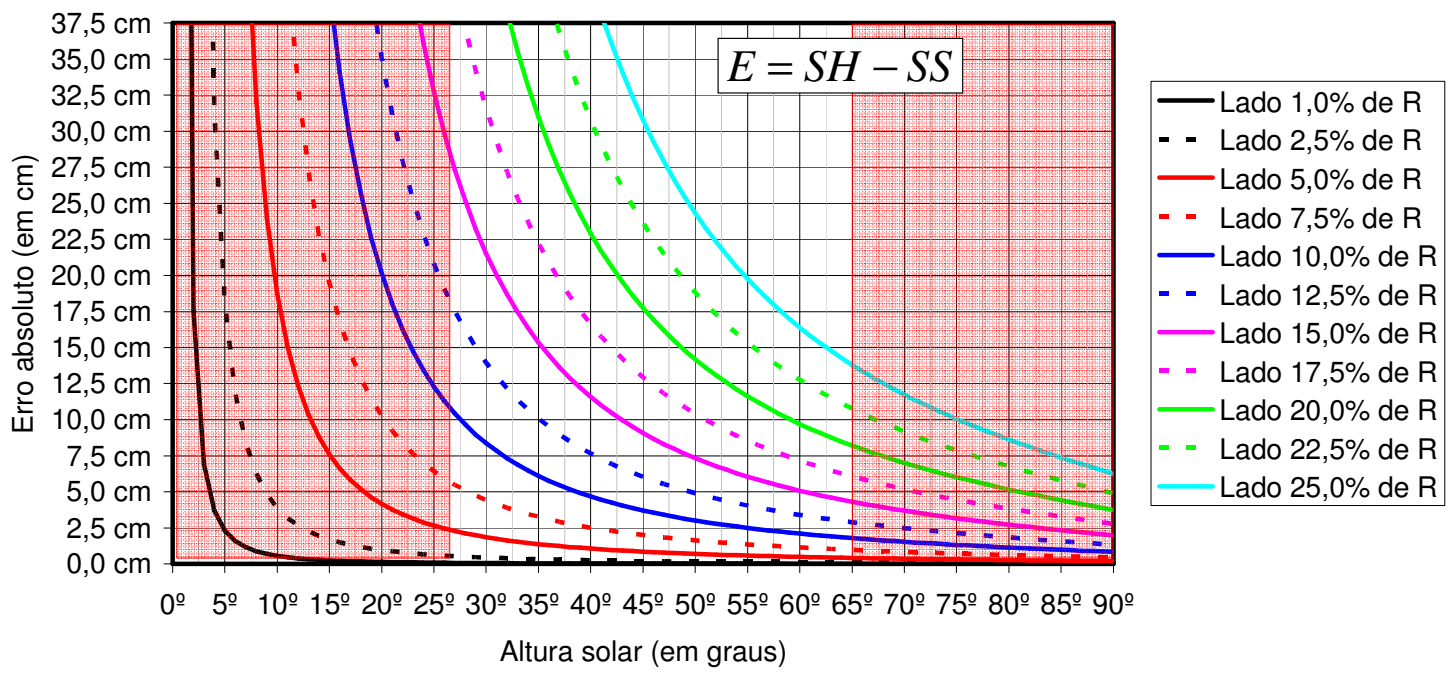

No Caso 2, para trabalhar com erro menor que $10 \%$ a altura máxima do objeto será aproximadamente $2,5 \%$ de $\mathrm{R}$, algo em torno de $3,75 \mathrm{~cm}$, operando com essa margem de erro entre $20^{\circ}-80^{\circ}$ de altura solar. Para erros menores que $20 \%$ a altura máxima deverá ser menor que $7,5 \%$ de $\mathrm{R}$ (neste caso $11,25 \mathrm{~cm}$ ), porém para uma faixa de altura solar mais reduzida, entre $35^{\circ}$ e $65^{\circ}$.

3.3 Caso 3 - Sombras projetadas no plano vertical

A Figura 9 apresenta o erro percentual (E/SS) para quando o objeto horizontal projeta sombras sobre um plano vertical.

\section{Figura 9 - Erro percentual X Altura solar}

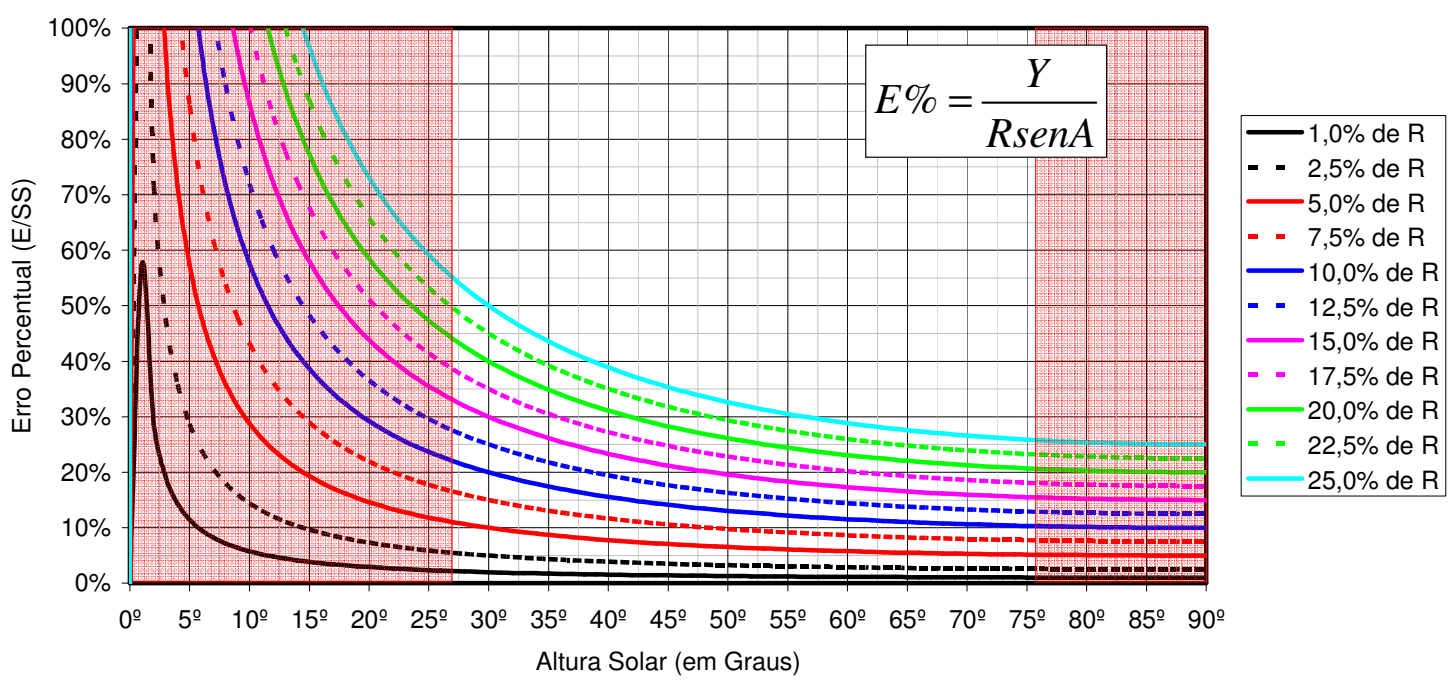

A Figura 10 apresenta o erro (em cm) em função da altura solar (ângulo A). 
Figura 10 - Erro (em cm) X Altura solar

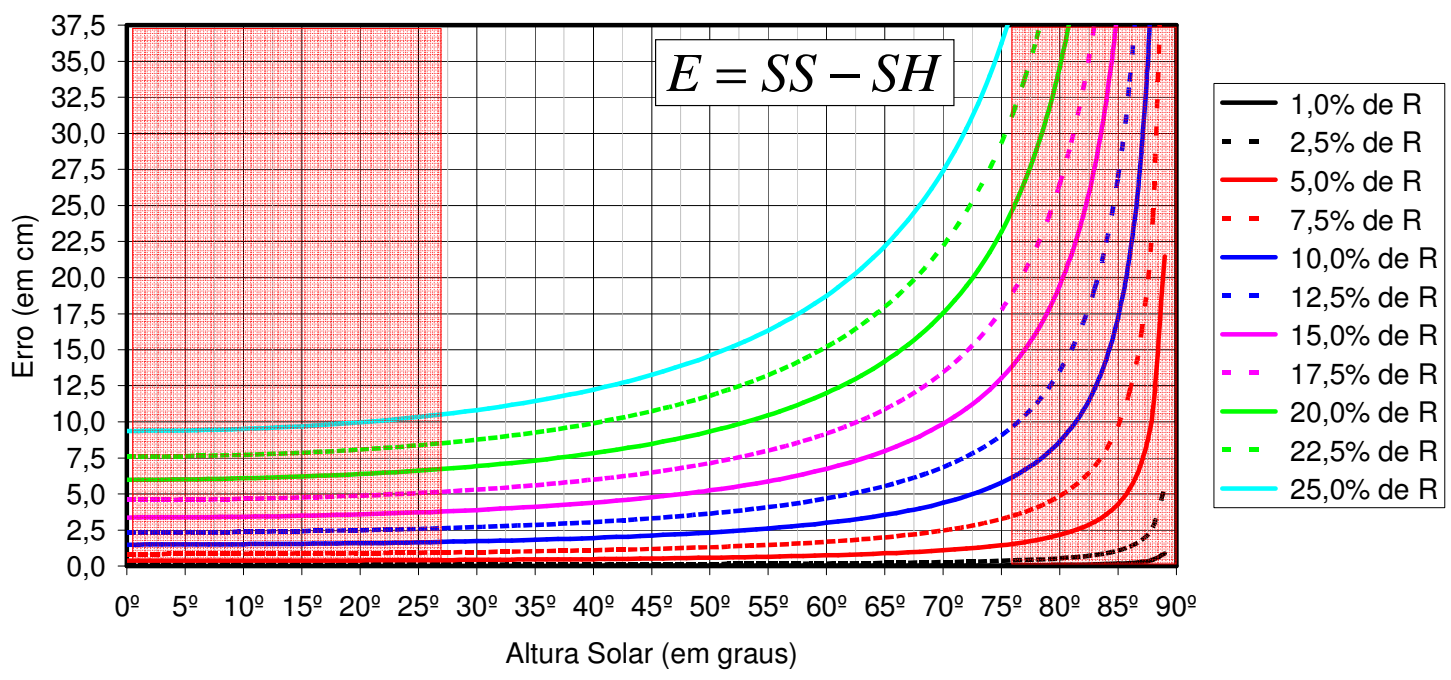

Sombras de objetos horizontais projetadas em superfícies verticais serão maiores quanto maior for a altura solar (ângulo A), tendendo ao infinito em ângulos próximos de $90^{\circ}$. Também neste caso, sombras excessivamente grandes quando comparadas com o objeto que as gera terão menor aplicação prática.

A Figura 9 mostra que o erro percentual é maior para alturas solares baixas. Já a Figura 10 mostra que, embora maior percentualmente, esse erro é pouco significativo em $\mathrm{cm}$.

Visando determinar uma faixa de alturas solares para análise objetiva do erro percentual, definiu-se para este caso o ângulo $27^{\circ}$ como limite inferior de uso do Heliodon (quando a altura solar gera sombra equivalente a $50 \%$ da medida da marquise) e $76^{\circ}$ como limite superior (quando a altura solar gera sombra equivalente a $400 \%$ da medida da marquise).

Chama atenção, conforme demonstrado pela Equação 10, que a medida X, profundidade da marquise, não influi na margem de erro. Esta é determinada pela altura do suporte da marquise.

No Caso 3, para trabalhar com erro menor que $10 \%$ a altura máxima do suporte da marquise será $7,5 \mathrm{~cm}$ (5\% de R). Para erros menores que $20 \%$ a altura máxima será aproximadamente $15 \mathrm{~cm}(10 \%$ de $\mathrm{R})$.

\section{CONSIDERAÇÕES FINAIS}

Após identificar as principais causas de diferenças geométricas (erros) entre sombras projetadas pelo sol e sombras projetadas pelo simulador apresentado foi possível: determinar o impacto das diferenças entre a geometria dos movimentos solares aparentes e a geometria dos movimentos simulador, avaliado como pouco significativo; e determinar margens de erro para diferentes dimensões de maquetes.

Os resultados obtidos evidenciaram que: o erro percentual não deve ser analisado isoladamente, deve ser vinculado às dimensões das sobras e objetos que às geram; os erros serão maiores nos horários próximos ao nascer e pôr do sol; as simulações de latitudes altas, que implicam em altitudes solares baixas quando simulado o inverno, apresentarão margens de erro importantes.

Quanto às margens de erro, maquetes com altura maior que 5\% de $\mathrm{R}$ apresentarão erros percentuais maiores que $10 \%$ em parte das faixas de alturas solares estudadas. O que 
pode restringir o uso do aparelho quando a precisão for importante, mas não diminui a importância deste tipo de aparelho quando o objetivo é ilustrar os movimentos solares. Os resultados apresentados permitem ao usuário especificar as dimensões da maquete em função do seu caso, do raio do heliodon utilizado, das margens de erro admitidas e das alturas solares que serão analisadas.

Os autores sugerem estudo visando estabelecer os limites percentuais dos erros nas dimensões das sombras segundo os erros dimensionais tolerados na industria da construção civil.

\section{REFERÊNCIAS BIBLIOGRÁFICAS}

BRUMFIEL, G. The astronomical unit gets fixed: Earth-Sun distance changes from slippery equation to single number. Nature News. April, 2012. Disponível em $<$ http://www.nature.com/news/the-astronomical-unit-gets-fixed-1.11416> Acesso em $20 \mathrm{de}$ marco de 2013.

CUNHA, E. G. da (org.). Elementos de arquitetura de climatização natural. $2^{\text {a }}$ edição. Porto Alegre: Masquatro, 2006.

FERNANDES, L. C.; CUNHA, E. DA. Ensino de Geometria Solar: Proposta de Heliodon Alternativo. In: XI Encontro Nacional de Conforto no Ambiente Construído e VII Encontro Latino Americano de Conforto no Ambiente Construído. Anais do ENCAC e ELACAC 2011. Armação de Búzios: 2011.

OLGYAY, Victor. Arquitectura y clima: manual de diseño bioclimático para arquitectos y urbanistas. $1^{a}$ edição. $5^{a}$ reimpressão. Espanha: Gustavo Gili, 2008.

SAMPAIO, J. L.; C. S. CALÇADA. Física: volume único. São Paulo: Atual, 2005.

SZOKOLAY, S. Solar Geometry. PLEA Notes. Passive and Low Energy Architecture International em associação com University of Queensland: Department of Architecture. 2007. Disponível em: <http://www.arct.cam.ac.uk/PLEA/Document>. Acesso em: 10 abr. 2011. 